\title{
Effect of Niacin on FGF23 Concentration in Chronic Kidney Disease
}

\author{
Madhumathi Rao ${ }^{a}$ Michael Steffes ${ }^{b}$ Andrew Bostom ${ }^{c}$ Joachim H. Ix ${ }^{d}$ \\ ${ }^{a}$ Division of Nephrology, Tufts Medical Center, Boston, Mass., ${ }^{b}$ Department of Pathology, University of Minnesota \\ Medical School, Minneapolis, Minn., 'Department of Medicine, Brown University, Providence, R.I., and d Division of \\ Nephrology-Hypertension, University of California San Diego, La Jolla, Calif., USA
}

\section{Key Words}

Niacin · Calcium · Phosphorus · Growth factor · Kidney

disease $\cdot$ Cardiovascular disease

\begin{abstract}
Background: Elevated serum phosphorus and FGF23 are independent cardiovascular risk factors in patients with chronic kidney disease. In a randomized controlled trial of patients with dyslipidemia assigned to either extended release niacin (ERN) alone, ERN combined with the selective prostaglandin $D_{2}$ receptor subtype 1 inhibitor laropiprant (ERN-L) or placebo, niacin lowered serum phosphorus; however, it is not known if it lowers FGF23 concentrations. Methods: This is an ancillary study to a multicenter, randomized, double-blind, placebo-controlled trial among patients with dyslipidemia and an estimated glomerular filtration rate (eGFR) of 30-74 $\mathrm{ml} / \mathrm{min} / 1.73 \mathrm{~m}^{2}$. Participants were randomized to ERN-L $(\mathrm{n}=$ $162)$, ERN $(n=97)$, or placebo $(n=68)$ in a 3:2:1 ratio for 24 weeks. The primary outcome was a change in serum FGF23 concentrations, and secondary outcomes were changes in other mineral metabolism parameters. Results: Both the ERN and ERN-L groups showed significant declines in serum phosphorus, calcium and calcium · phosphorus product at 24 weeks compared to placebo. A significant decline from baseline $(10.9 \%, p<0.01)$ in the serum FGF23 concentration was
\end{abstract}

observed in the ERN group compared to placebo, but not in the ERN-L group compared to placebo ( $p=0.36$ and 0.97 for ERN-L and placebo, respectively), despite equivalent declines in serum phosphorus. Similarly, the most marked declines in PTH occurred in the ERN-only group versus placebo; no change in PTH was observed in the ERN-L group. Conclusions: In this ancillary study of hyperlipidemic patients with an eGFR of $30-74 \mathrm{ml} / \mathrm{min} / 1.73 \mathrm{~m}^{2}$, ERN alone but not in combination with laropiprant lowered FGF23 and PTH concentrations. If confirmed, niacin may provide a novel strategy to decrease phosphorus, FGF23, and PTH concentrations in patients with chronic kidney disease.

๑) 2014 S. Karger AG, Basel

\section{Introduction}

Hormones that influence phosphorus metabolism are altered early in the course of chronic kidney disease (CKD) [1]. However, serum concentrations of phosphorus are maintained within normal limits until the glomerular filtration rate (GFR) falls to less than approximately $35 \mathrm{ml} / \mathrm{min} / 1.72 \mathrm{~m}^{2}$ [1]. It is now well known that higher serum phosphorus concentrations are associated with death, cardiovascular events, and vascular calcification in human studies, both in the general population

\section{KARGER}

E-Mail karger@karger.com www.karger.com/ajn
(C) 2014 S. Karger AG, Basel

0250-8095/14/0396-0484\$39.50/0
Joachim H. Ix, MD, MAS

Division of Nephrology-Hypertension, Department of Medicine University of California San Diego and San Diego VA Healthcare System 3350 La Jolla Village Drive, Mail Code 111-H, San Diego, CA 92161 (USA) E-Mail joeix@ ucsd.edu 
and among patients with CKD. Such associations are evident even at phosphorus concentrations that remain within the normal laboratory range. Greater concentrations of fibroblast growth factor-23 (FGF23) [2-4] constitute one of the earliest physiological trade-offs to maintain renal phosphorus clearance in the face of declining GFR. Recent reports link these elevations in circulating FGF23 to multiple adverse outcomes including cardiovascular disease (CVD) and kidney disease progression [5-9], and suggest that during the earlier stages of CKD [2] FGF23 may be a more sensitive biomarker of phosphorus metabolism than serum phosphorus concentrations.

Given consistent associations of phosphorus concentrations with CVD, we and others have hypothesized that phosphorus lowering may lead to a reduction of cardiovascular risk among patients with CKD. However, recent studies have demonstrated that use of oral phosphorus binders have little effect on serum phosphorus concentrations in CKD [10-13]. In contrast, the phosphorus-lowering effects of niacin have recently been recognized [1416]. Niacin and niacinamide inhibit active sodium-dependent intestinal phosphorus co-transport in the small bowel; this transport mechanism is responsible for approximately $50 \%$ of intestinal phosphorus absorption $[15,17,18]$. Studies in patients with end-stage renal disease have suggested that niacin may have hypophosphatemic effects comparable to calcium acetate or sevelamer $[19,20]$, although less is known in CKD. In post hoc analysis from a placebo-controlled trial of patients who had dyslipidemia and were randomly assigned to extended release niacin (ERN) alone, ERN combined with the selective prostaglandin $\mathrm{D}_{2}\left(\mathrm{PGD}_{2}\right)$ receptor subtype 1 inhibitor laropiprant (ERN-L), or placebo, niacin had a phosphorus-lowering effect across a broad range of kidney function. Robust declines in phosphorus were seen among those with or without $\mathrm{CKD}$, and were sustained for at least 6 months of therapy [21-24].

Beyond changes in serum phosphorus, it may also be advantageous to lower serum FGF23 concentrations. Whether dietary phosphorus restriction or phosphorus binders have downstream effects on FGF23 concentrations have been addressed in preliminary studies with variable results [11-13]. However, to our knowledge, no prior study has examined whether niacin influences FGF23 concentrations. In the present study, we report the effects of ERN and ERN-L versus placebo on FGF23 concentrations and on other mineral metabolism parameters among subjects with an eGFR of $30-74 \mathrm{ml} / \mathrm{min} / 1.73 \mathrm{~m}^{2}$ enrolled in this trial.

\section{Methods}

\section{Participants}

Details of the parent study are described in the completed clinical trial reported by Maccubbin et al. (NCT00269204) [23, 25]. Briefly, the parent study was a worldwide, multicenter, randomized, double-blind, placebo-controlled, parallel-group trial with a 24-week treatment period preceded by a 4 -week placebo run-in period. Patients who had primary hypercholesterolemia or mixed dyslipidemia and whose serum creatinine was $\leq 1.7 \mathrm{mg} / \mathrm{dl}$ were assigned to initiate treatment with ERN-L, ERN ( $1 \mathrm{~g})$, or placebo in a 3:2:1 ratio. ERN-L consists of a fixed-dose combination tablet containing $1 \mathrm{~g}$ of ERN and $20 \mathrm{mg}$ of laropiprant. Laropiprant is a potent, once-daily, highly selective $\mathrm{PGD}_{2}$ receptor subtype 1 antagonist that has been shown to reduce the incidence and intensity of niacin-induced flushing [26] and acts independent of niacin's lipid-modifying pathway [27]. Study drug allocation was stratified by ongoing statin use and study site. After 4 weeks of double-blind treatment, doses were doubled (two tablets), increasing the ERN-L dosages to $2 \mathrm{~g} / 40 \mathrm{mg}$ and the ERN dosage to $2 \mathrm{~g}$ for the remaining 20 weeks. Patients were instructed to take the study drug or placebo once daily with food in the evening. There were nine scheduled clinic visits at weeks $-4,-2,0,2,4,8,12,18$, and 24 . The study protocol was reviewed and approved by the appropriate ethics committees/institutional review boards, and all patients provided written informed consent. The study was conducted under the guidelines established by the Declaration of Helsinki and Good Clinical Practice standards.

\section{Measurements}

Laboratory determinations were performed on fasting serum samples. After separation, serum was immediately transferred into cryovials, refrigerated at $4^{\circ} \mathrm{C}$, and shipped overnight under refrigerated conditions to the central laboratory (PPD Global Central Laboratories, Highland Heights, Ky., USA, or Zaventem, Belgium) for analyses within several hours of receipt. Concentrations of serum phosphorus, calcium, and albumin were determined using photometric methods and of serum creatinine by the Jaffe kinetic method, on a Roche modular automated clinical chemistry analyzer.

Serum calcium concentrations were adjusted for serum albumin concentrations $<4 \mathrm{~g} / \mathrm{dl}$ using the following formula: Corrected total calcium $(\mathrm{mg} / \mathrm{dl})=$ total calcium $(\mathrm{mg} / \mathrm{dl})+0.8 \times[4-$ serum albumin $(\mathrm{g} / \mathrm{dl})$ ] [28]. eGFR was calculated from the creatininebased Chronic Kidney Disease Epidemiology Collaboration (CKD-EPI) formula [29, 30]. Glycemic status was determined before randomization for the parent study and designated 'normal,' 'impaired,' or 'diabetes' on the basis of medical history, laboratory evaluations, and clinical judgment. Only the assignment of 'diabetes' was used for analyses comparing diabetic and non-diabetic strata.

Intact serum FGF23, parathyroid hormone (PTH) and vitamin $\mathrm{D}(25-\mathrm{OHD})$ concentrations were measured in banked sera (stored at $-70^{\circ} \mathrm{C}$ ) available from the baseline (week 0 ) and final follow-up (week 24) visits among 327 patients who had an eGFR of 30-74 $\mathrm{ml} / \mathrm{min} / 1.73 \mathrm{~m}^{2}$ at baseline. There were 219 individuals in the original study with an eGFR of $<60 \mathrm{ml} / \mathrm{min} / 1.73 \mathrm{~m}^{2}$ and were our original target population. Only 109 of these had sufficient residual blood volume to allow measurement of FGF23 at both the baseline and week 24 time-point. Thus we expanded our eGFR inclusion 
Table 1. Baseline characteristics by treatment assignment

\begin{tabular}{|c|c|c|c|c|c|}
\hline & All $(n=327)$ & ERN-L $(n=162)$ & $\mathrm{ERN}(\mathrm{n}=97)$ & Placebo $(n=68)$ & $\mathrm{p}$ value \\
\hline \multicolumn{6}{|c|}{ Demographic and comorbid characteristics } \\
\hline Age, years & $61 \pm 10$ & $62 \pm 11$ & $61 \pm 10$ & $61 \pm 9$ & 0.65 \\
\hline Female & $49(159)$ & $46(75)$ & $46(45)$ & $56(38)$ & 0.37 \\
\hline Race & & & & & 0.88 \\
\hline White & $79(258)$ & $79(128)$ & $75(73)$ & $84(57)$ & \\
\hline Black & $5(17)$ & $4(7)$ & $6(6)$ & $4(3)$ & \\
\hline Other & $3(9)$ & $2(4)$ & $3(3)$ & $3(3)$ & \\
\hline Statin use & $65(213)$ & $65(106)$ & $60(58)$ & $72(49)$ & 0.26 \\
\hline Diabetes & $21(67)$ & $22(35)$ & $18(17)$ & $22(15)$ & 0.68 \\
\hline $\mathrm{eGFR}, \mathrm{ml} / \mathrm{min} / 1.73 \mathrm{~m}^{2}$ & $63 \pm 9$ & $63 \pm 9$ & $63 \pm 8$ & $62 \pm 9$ & 0.68 \\
\hline $\mathrm{eGFR}<60 \mathrm{ml} / \mathrm{min} / 1.73 \mathrm{~m}^{2}$ & $109(33)$ & $59(36)$ & $28(29)$ & $22(32)$ & 0.40 \\
\hline Albumin, g/dl & $4.4 \pm 0.3$ & $4.4 \pm 0.3$ & $4.4 \pm 0.2$ & $4.4 \pm 0.3$ & 0.12 \\
\hline Calcium $\cdot$ phosphorus & $32 \pm 5$ & $31.4 \pm 5.2$ & $32.1 \pm 4.7$ & $32.6 \pm 5.4$ & 0.22 \\
\hline $25-\mathrm{OHD}, \mathrm{ng} / \mathrm{ml}^{\dagger}$ & $22 \pm 8$ & $21 \pm 9$ & $22 \pm 8$ & $23 \pm 9$ & 0.50 \\
\hline PTH, pg/ml*, & $40.7 \pm 1.0$ & $36.0 \pm 1.1$ & $37.1 \pm 1.1$ & $34.7 \pm 1.1$ & 0.81 \\
\hline FGF23, pg/ml* & $40.7 \pm 1.0$ & $39.0 \pm 1.0$ & $44.0 \pm 1.0$ & $40.5 \pm 1.0$ & 0.04 \\
\hline
\end{tabular}

Data show means \pm SD or $\%(n)$, unless otherwise specified. * Geometric mean \pm SEM. ${ }^{\dagger} 25$-OHD concentrations were available in 314 individuals (placebo $=67, \mathrm{ERN}=93, \mathrm{ERN}-\mathrm{L}=154$ ); PTH concentrations were available in a subset of 97 individuals $($ placebo $=18$, $\mathrm{ERN}=34$, ERN-L $=45$ ).

criteria upwards to $74 \mathrm{ml} / \mathrm{min} / 1.73 \mathrm{~m}^{2}$ based on available specimens and research funds available for measurements. FGF23 concentrations were measured using a two-site enzyme-linked immunosorbent assay (ELISA) (Kainos Laboratories, Inc., Tokyo, Japan). A sample was incubated in a microtiter well with two antibodies that recognize full-length FGF23: a capture antibody coated to the plate well and an HRP-conjugated detection antibody. FGF23 contained in the sample was immunologically bound by the capture antibody and the detection antibody to form a sandwich complex. PTH concentrations were measured in serum on a Roche Elecsys 2010 Analyzer (Roche Diagnostics Corp.) using a sandwich immunoassay method (Roche Diagnostics, Indianapolis, Ind., USA). 25-OH vitamin D (25-OHD) was measured in serum using liquid chromatography/tandem mass spectrometry.

\section{Statistical Analysis}

Baseline descriptive statistics included means $\pm \mathrm{SD}$, quantiles, and frequencies. Changes in serum phosphorus, calcium, calcium - phosphorus product, FGF23, PTH and 25-OHD concentrations were expressed as means \pm SD (geometric means \pm SEM for variables that were log-transformed), and compared across the three randomized treatment groups using ANOVA.

The primary objective of this analysis was to examine the changes in serum FGF23 concentrations over the period of the study on the basis of measurements taken at baseline and at 24 weeks across the three intervention groups. The factors determining the changes in serum FGF23 concentrations over the period of the study were also analyzed using a General Linear Model including an interaction term with treatment assignment.

All statistical analyses were performed using SPSS version 14 software. All tests were two-tailed; the $\alpha$-level was set to 0.05 . Confidence intervals (CI) were calculated at the 95\% level.

\section{Results}

Among the 327 study participants, characteristics at baseline were generally comparable across the treatment arms (table 1), although FGF23 concentrations were slightly higher in the ERN arm, and slightly lower in the ERN-L arms compared to placebo $(\mathrm{p}=0.04)$.

Table 2 shows that both the ERN and ERN-L groups showed significant declines in serum phosphorus, calcium, and calcium - phosphorus product at 24 weeks compared to placebo. When the niacin groups were pooled, the mean declines were $-0.5 \pm 0.4 \mathrm{mg} / \mathrm{dl}$ for serum phosphorus, -0.2 $\pm 0.4 \mathrm{mg} / \mathrm{dl}$ for serum calcium, and $-4.8 \pm 4.6$ for the calcium - phosphorus product compared to baseline values (post-hoc Tukey's test showed no significant differences between ERN and ERN-L). In contrast, there was no change 
Table 2. Change in mineral metabolites over 24 weeks by treatment assignment

\begin{tabular}{|c|c|c|c|c|}
\hline & $\begin{array}{l}\text { ERN-L } \\
(\mathrm{n}=162)\end{array}$ & $\begin{array}{l}\text { ERN } \\
(n=97)\end{array}$ & $\begin{array}{r}\text { Placebo } \\
(\mathrm{n}=68)\end{array}$ & $\begin{array}{l}\mathrm{p} \\
\text { value }\end{array}$ \\
\hline \multicolumn{5}{|c|}{ FGF23, pg/ml* } \\
\hline Baseline & $39.0 \pm 1.0$ & $44 \pm 1.0$ & $40.6 \pm 1.0$ & 0.04 \\
\hline Week 24 & $40.0 \pm 1.0$ & $40.1 \pm 1.0$ & $40.6 \pm 1.1$ & 0.92 \\
\hline Change $^{\ddagger}$ & $1.7 \pm 13.9$ & $-4.8 \pm 18.9$ & $1.2 \pm 18.4$ & $<0.01$ \\
\hline \multicolumn{5}{|c|}{ PTH, pg/ml ${ }^{*, \dagger}$} \\
\hline Baseline & $36.0 \pm 1.1$ & $37.1 \pm 1.1$ & $34.7 \pm 1.1$ & 0.81 \\
\hline Week 24 & $32.0 \pm 1.1$ & $28.8 \pm 1.1$ & $31.1 \pm 1.1$ & 0.51 \\
\hline Change $^{\ddagger}$ & $-1.8 \pm 13.1$ & $-9.0 \pm 11.0$ & $-3.7 \pm 8.9$ & 0.03 \\
\hline \multicolumn{5}{|c|}{ Phosphorus, mg/dl } \\
\hline Baseline & $3.3 \pm 0.5$ & $3.4 \pm 0.4$ & $3.4 \pm 0.5$ & 0.32 \\
\hline Week 24 & $2.9 \pm 0.5$ & $2.9 \pm 0.5$ & $3.4 \pm 0.6$ & $<0.001$ \\
\hline Change $^{\ddagger}$ & $-0.5 \pm 0.4$ & $-0.4 \pm 0.5$ & $0.0 \pm 0.6$ & $<0.001$ \\
\hline \multicolumn{5}{|c|}{ Calcium, mg/dl } \\
\hline Baseline & $9.5 \pm 0.4$ & $9.5 \pm 0.4$ & $9.6 \pm 0.3$ & 0.35 \\
\hline Week 24 & $9.3 \pm 0.4$ & $9.3 \pm 0.4$ & $9.5 \pm 0.3$ & $<0.001$ \\
\hline Change $^{\ddagger}$ & $-0.2 \pm 0.4$ & $-0.2 \pm 0.4$ & $0.0 \pm 0.3$ & 0.003 \\
\hline \multicolumn{5}{|c|}{ Calcium $\cdot$ phosphorus } \\
\hline Baseline & $31.4 \pm 5.2$ & $32.1 \pm 4.7$ & $32.6 \pm 5.4$ & 0.22 \\
\hline Week 24 & $26.6 \pm 4.7$ & $27.3 \pm 5.2$ & $32.7 \pm 5.9$ & $<0.001$ \\
\hline Change & $-4.8 \pm 4.4$ & $-4.8 \pm 4.9$ & $0.08 \pm 6.2$ & $<0.001$ \\
\hline \multicolumn{5}{|c|}{ Creatinine, $\mathrm{mg} / \mathrm{dl}$} \\
\hline Baseline & $1.1 \pm 0.2$ & $1.1 \pm 0.2$ & $1.1 \pm 0.2$ & 0.96 \\
\hline Week 24 & $1.1 \pm 0.2$ & $1.1 \pm 0.2$ & $1.1 \pm 0.2$ & 0.86 \\
\hline Change $e^{\ddagger}$ & $-0.01 \pm 0.1$ & $-0.01 \pm 0.1$ & $-0.01 \pm 0.1$ & 0.41 \\
\hline \multicolumn{5}{|c|}{$25-\mathrm{OHD}, \mathrm{ng} / \mathrm{ml}^{\dagger}$} \\
\hline Baseline & $21 \pm 9$ & $22 \pm 8$ & $23 \pm 9$ & 0.50 \\
\hline Week 24 & $26 \pm 9$ & $26 \pm 8$ & $27 \pm_{7}$ & 0.33 \\
\hline Change $^{\ddagger}$ & $4 \pm 7$ & $4 \pm 6$ & $4 \pm 8$ & 0.80 \\
\hline
\end{tabular}

Data show means \pm SD, unless otherwise specified. * Geometric mean \pm SEM. ${ }^{\dagger} 25$-OHD concentrations were available in 314 individuals (placebo $=67, \mathrm{ERN}=93, \mathrm{ERN}-\mathrm{L}=154$ ); PTH concentrations were available in a subset of 97 individuals (placebo $=18$, $\mathrm{ERN}=34, \mathrm{ERN}-\mathrm{L}=45) .{ }^{\ddagger}$ Change normally distributed for all variables.

compared to baseline in the placebo group. We also did not observe a significant change in creatinine or 25-OHD concentrations over 24 weeks in any treatment group.

The change in FGF23 concentration at 24 weeks was significantly different across the three randomization groups $(\mathrm{p}<0.01)$. We observed a $10.9 \%$ decline from baseline in the ERN group (table 2; fig. 1b). This change differed in the ERN group compared to the placebo group $(\mathrm{p}=0.06)$ and also comparing the ERN group to the ERNL group ( $\mathrm{p}<0.01)$. FGF23 concentrations did not decline significantly in the ERN-L group compared to placebo $(\mathrm{p}=0.97)$, despite similar declines in serum phosphorus concentrations (Tukey's test for paired comparisons).

Niacin and FGF23 in CKD

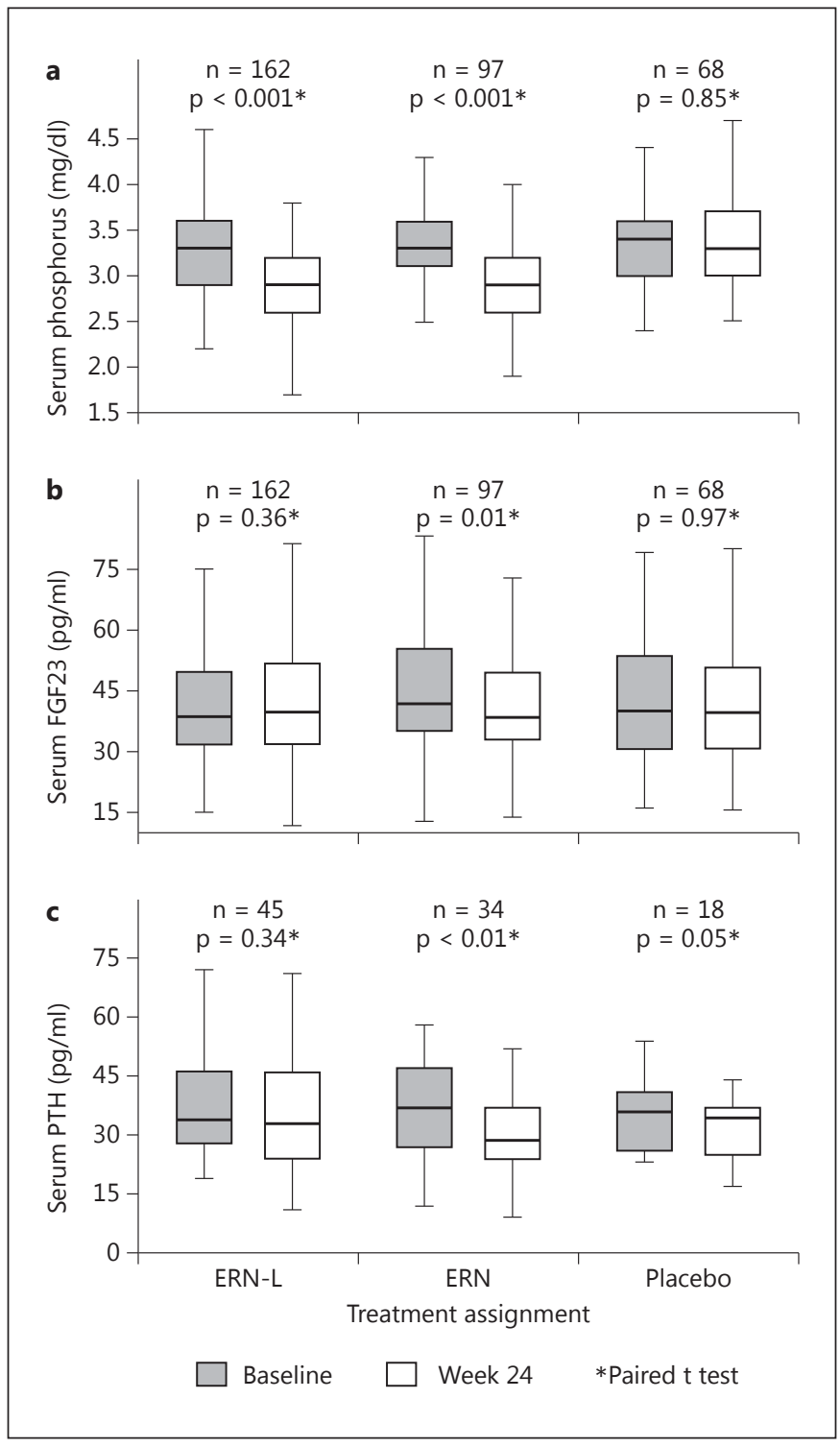

Fig. 1. a-c Box plots showing serum phosphorus (a), FGF23 (b) and PTH (c) concentrations at baseline and at 24 weeks in each of the three group assignments. A significant decline in serum FGF23 concentrations is seen in the ERN group, but not in the ERN-L or placebo groups.

Sufficient serum was available for PTH measurement in a subset of 97 individuals. This subgroup was similar with respect to age, sex, race, and baseline eGFR to the overall study population (data not shown). Similar to results for FGF23, we noted the most marked declines in PTH in the ERN-only group versus placebo; whereas no change in PTH was observed in the ERN-L group (table 2; fig. 1c). 
The determinants of the change in FGF23 concentrations across all three treatment groups were examined (online suppl. table 1; for all online suppl. material, see www. karger.com/doi/10.1159/000362424). The change in serum phosphorus was the strongest determinant; for each $\mathrm{mg} / \mathrm{dl}$ decrease in serum phosphorus during follow-up, FGF23 concentrations decreased by $6.6 \mathrm{pg} / \mathrm{ml}$ (95\% CI, 3.1-10.2). Baseline FGF23 concentrations were also a significant predictor of change in FGF23. For each $\mathrm{pg} / \mathrm{ml}$ higher baseline FGF23 concentration, FGF23 concentrations declined by $-0.4 \mathrm{pg} / \mathrm{ml}(95 \% \mathrm{CI},-0.5$ to -0.3$)$ over the 24 -week study. The fully adjusted model explained $27 \%$ of the variance of the change in FGF23 concentrations over the study period. This model included change in serum phosphorus, the baseline FGF23 concentrations, treatment intervention as well as the interaction of the change in serum phosphorus with the treatment intervention. Compared with patients assigned to placebo, patients assigned to the ERN group had a greater decline in FGF23 concentrations for the same change in serum phosphorus.

\section{Discussion}

In this randomized double-blind study evaluating ERN and ERN-L versus placebo in 327 dyslipidemic patients with an eGFR between 30 and $74 \mathrm{ml} / \mathrm{min} / 1.73 \mathrm{~m}^{2}$, we observed that treatment with ERN led to a decline in FGF23 concentrations by approximately $11 \%$ from baseline over 24 weeks. At the same time, we observed no significant effect of ERN-L on FGF23 concentrations compared to placebo. We noted a similar pattern between treatment assignment and serum PTH concentrations, with a decline in the ERN-only group versus placebo, whereas no change in PTH was observed in the ERN-L group. We observed that the magnitude of serum phosphorus lowering during the follow-up period was associated with greater declines in FGF23 during follow-up, and patients assigned to the ERN group had a greater decline in FGF23 concentrations for the same change in serum phosphorus.

In the trade-off to maintain normal phosphorus concentrations as GFR declines in CKD, progressive increases in serum FGF23 and PTH concentrations occur $[2,4]$. Prospective studies in pre-dialysis $\mathrm{CKD}$, incident and prevalent end-stage renal disease, and kidney transplant recipients demonstrate that elevated FGF23 concentrations are independently associated with progression of CKD and development of CVD events and mortality $[1,2$, $4,31]$. While KDIGO recommends keeping phosphorus within the normal reference range in CKD stage 3-5, most such patients have normal phosphorus concentrations [32] and may nonetheless have abnormally high FGF23 and PTH concentrations. While there is evidence from observational studies that use of phosphate binders among patients with CKD with serum phosphorus predominantly in the normal range lowers the risk of mortality by nearly $40 \%$ [33], investigators have suggested that perhaps FGF23 should be a target for randomized clinical trials rather than phosphorus [13]. However, prior studies have been conflicting about the efficacy of intestinal phosphorus binders or dietary phosphorus restriction on circulating FGF23 concentrations. Given the marked reductions in phosphorus observed with niacin in prior studies, we hypothesized it might also lower FGF23. We had no a priori hypothesis that the effect of ERN on FGF23 would differ by concomitant laropiprant use. Thus, our results only partially confirmed our hypothesis, as the ERN-only arm lowered FGF23, whereas ERN-L did not.

The mechanisms to explain differential effects of ERN versus ERN-L on FGF23 are uncertain. Laropiprant is a selective $\mathrm{PGD}_{2}$ receptor subtype 1 inhibitor that reduces niacin-induced flushing $[25,34]$. It appears clear from our analysis, and the earlier reports from the parent trial, that laropiprant did not interfere with the phosphorus-lowering effect of niacin. However, whether it may have a role in the phosphorus-sensing axis that might differentially affect FGF23 homeostasis is unknown. The mechanism by which serum phosphorus concentrations translate to regulation of FGF23 secretion in bone cells, and whether prostaglandin inhibitors impact this axis, is presently unknown. In vitro data suggest that $\mathrm{PGD}_{2}$ stimulates sodium-dependent phosphorus uptake in proliferating MC3T-E1 osteoblast-like cells. Both osteoblasts and osteoclasts are influenced by the $\mathrm{D}$-type prostanoid receptor [35-37]. Thus, if there are truly differential effects of ERN versus ERN-L on serum FGF23 concentrations, then laropiprant alone may interfere with phosphate sensing or uptake by bone cells and influence FGF23 regulation. We also observed that ERN lowered PTH, whereas ERN-L did not. PTH is known to stimulate FGF23 generation $[3,38]$, but any putative effects of laropiprant on $\mathrm{PTH}$ regulation are unknown. If laropiprant increased PTH, then PTHinduced upregulation of FGF23 is another possible mechanism consistent with our results. At the current time, laropiprant has been withdrawn from the market but may yet provide an interesting avenue of research to understand the mechanisms of regulation of FGF23 and PTH.

The effect of niacin on FGF23 lowering appeared to be related to the magnitude of phosphorus lowering. Inter- 
estingly, FGF23 lowering by niacin treatment also appeared to be most dramatic among patients who had the highest FGF23 concentrations at baseline. While it is possible that the therapeutic advantage of niacin for FGF23 lowering may be realized only beyond a threshold of clinically significant physiological derangements in mineral metabolism parameters, there are alternative explanations. Differences in dietary phosphorus intake between the ERN and ERN-L interventions could be speculated, but intestinal side effects were not dissimilar in the two arms. Assessment of dietary phosphorus intake would have been valuable as would have serum $1,25(\mathrm{OH})_{2} \mathrm{D}_{3}$ concentrations, but these were not available in the parent study. A third possibility is regression to the mean. At baseline, both the placebo and ERN-L groups had FGF23 levels of approximately $40 \mathrm{pg} / \mathrm{ml}$, and did not change significantly during follow-up. In contrast, the ERN group had baseline FGF23 levels of approximately $44 \mathrm{pg} / \mathrm{ml}$ at baseline, and came down to approximately $40 \mathrm{pg} / \mathrm{ml}$ at follow-up. It is possible that each treatment groups' true average FGF23 level was $40 \mathrm{pg} / \mathrm{ml}$ at baseline, and that the higher level observed in those randomized to ERN was a chance finding rather than due to biological effects of the drug. However, the ERN group also experienced greater PTH reduction than either the placebo or ERN-L group, suggesting the observations more likely reflect biological effects of ERN then chance. Future studies will be required to confirm our findings. Finally, given the complexity of FGF23 regulation, simply lowering serum phosphate may not be sufficient to achieve FGF23 lowering, a point that should be considered when using FGF23 as a target for intervention for clinical end-points.

There was a $6.0 \mathrm{pg} / \mathrm{ml}$ relative difference in change in FGF23 comparing the ERN and placebo arms in our study (FGF23 decreased by $4.8 \mathrm{pg} / \mathrm{ml}$ in the ERN arm versus a $1.2 \mathrm{pg} / \mathrm{ml}$ increase in the placebo arm). The clinical significance of this magnitude of change in FGF23 is uncertain. Some prior studies have suggested more dramatic changes in FGF23 with certain binders, while other studies have not. Still others have found varying results of binders depending upon the FGF23 assay that was used $[10,39]$. Thus, whether ERN or binders are more effective in influencing FGF23 is presently uncertain and will require a study designed with both a binder and ERN arm. Moreover, FGF23 is extremely strongly associated with CVD events [31, 40], an association that is consistently stronger than that of serum phosphate with the same endpoint [41-44]. If this association proves to be causal, then even very modest decreases in FGF23 may ultimately prove to be clinically relevant.

In summary, in this randomized, double-blind, placebo-controlled trial among hyperlipidemic patients with an eGFR of $30-74 \mathrm{ml} / \mathrm{min} / 1.73 \mathrm{~m}^{2}$, ERN alone, but not in combination with laropiprant, lowered FGF23 and PTH concentrations. If these findings are confirmed, niacin may be a practical intervention strategy to simultaneously lower phosphorus and FGF23 concentrations among patients with CKD.

\section{Acknowledgements}

NCT00269204 was sponsored by Merck, Sharp \& Dohme Corp. Additional support was provided from the National Institutes of Diabetes, Digestive and Kidney Diseases (1R01DK10172001 ) to Dr. Ix. Funding for the assays for FGF23, PTH and 25-OHD was provided in a separate grant by Merck, Sharp \& Dohme Corp. Dr. Ix has received honoraria from Keryx Biopharmaceuticals and Shire Pharmaceuticals.

\section{References}

1 Kendrick J, Kestenbaum B, Chonchol M: Phosphate and cardiovascular disease. Adv Chronic Kidney Dis 2011;18:113-119.

2 Gutierrez OM: Fibroblast growth factor-23 and disordered vitamin $\mathrm{d}$ metabolism in chronic kidney disease: updating the 'tradeoff hypothesis. Clin J Am Soc Nephrol 2010.

$>3$ Wolf M: Forging forward with 10 burning questions on FGF23 in kidney disease. J Am Soc Nephrol 2010;21:1427-1435.

$\checkmark 4$ Wolf M: Update on fibroblast growth factor-23 in chronic kidney disease. Kidney Int 2012;82:737-747.

5 Gutierrez OM, Januzzi JL, Isakova T, Laliberte K, Smith K, Collerone G, Sarwar A, Hoffmann U, Coglianese E, Christenson R, et al: Fibroblast growth factor-23 and left ventricular hypertrophy in chronic kidney disease. Circulation 2009;119:2545-2552.

6 Gutierrez OM, Mannstadt M, Isakova T, Rauh-Hain JA, Tamez H, Shah A, Smith K, Lee H, Thadhani R, Juppner H, et al: Fibroblast growth factor-23 and mortality among patients undergoing hemodialysis. N Engl J Med 2008;359:584-592.

$\checkmark 7$ Mirza MA, Larsson A, Lind L, Larsson TE: Circulating fibroblast growth factor-23 is associated with vascular dysfunction in the community. Atherosclerosis 2009;205:385390.

8 Wolf M, Molnar MZ, Amaral AP, Czira ME, Rudas A, Ujszaszi A, Kiss I, Rosivall L, Kosa J,
Lakatos $\mathrm{P}$, et al: Elevated fibroblast growth factor-23 is a risk factor for kidney transplant loss and mortality. J Am Soc Nephrol 2011;22: 956-966.

9 Fliser D, Kollerits B, Neyer U, Ankerst DP, Lhotta K, Lingenhel A, Ritz E, Kronenberg F, Kuen E, Konig P, et al: Fibroblast growth factor-23 predicts progression of chronic kidney disease: the Mild to Moderate Kidney Disease (MMKD) Study. J Am Soc Nephrol 2007;18: 2600-2608.

10 Block GA, Wheeler DC, Persky MS, Kestenbaum B, Ketteler M, Spiegel DM, Allison MA, Asplin J, Smits G, Hoofnagle AN, et al: Effects of phosphate binders in moderate CKD. J Am Soc Nephrol 2012;23:1407-1415. 
11 Gonzalez-Parra E, Gonzalez-Casaus ML, Galan A, Martinez-Calero A, Navas V, Rodriguez $\mathrm{M}$, Ortiz A: Lanthanum carbonate reduces FGF23 in chronic kidney disease stage 3 patients. Nephrol Dial Transplant 2011;26: 2567-2571.

12 Isakova T, Gutierrez OM, Smith K, Epstein M, Keating LK, Juppner H, Wolf M: Pilot study of dietary phosphorus restriction and phosphorus binders to target fibroblast growth factor-23 in patients with chronic kidney disease. Nephrol Dial Transplant 2010;26: 584-591.

-13 Oliveira RB, Cancela AL, Graciolli FG, Dos Reis LM, Draibe SA, Cuppari L, Carvalho AB, Jorgetti V, Canziani ME, Moyses RM: Early control of PTH and FGF23 in normophosphatemic CKD patients: a new target in CKDMBD therapy? Clin J Am Soc Nephrol 2010; 5:286-291.

14 Ahmed MH: Niacin as potential treatment for dyslipidemia and hyperphosphatemia associated with chronic renal failure: the need for clinical trials. Ren Fail 2010;32:642-646.

15 Bostom AG: Binder blinders-niacin of omission? Am J Kidney Dis 2010;55:628-630.

- 16 Sampathkumar K, Selvam M, Sooraj YS, Gowthaman S, Ajeshkumar RN: Extended release nicotinic acid - a novel oral agent for phosphate control. Int Urol Nephrol 2006;38: 171-174.

17 Eto N, Miyata Y, Ohno H, Yamashita T: Nicotinamide prevents the development of hyperphosphataemia by suppressing intestinal sodium-dependent phosphate transporter in rats with adenine-induced renal failure. Nephrol Dial Transplant 2005;20:1378-1384.

- 18 Katai K, Tanaka H, Tatsumi S, Fukunaga Y, Genjida K, Morita K, Kuboyama N, Suzuki T, Akiba T, Miyamoto K, et al: Nicotinamide inhibits sodium-dependent phosphate cotransport activity in rat small intestine. Nephrol Dial Transplant 1999;14:1195-1201.

19 Cheng SC, Young DO, Huang Y, Delmez JA, Coyne DW: A randomized, double-blind, placebo-controlled trial of niacinamide for reduction of phosphorus in hemodialysis patients. Clin J Am Soc Nephrol 2008;3:11311138.

-20 Muller D, Mehling H, Otto B, Bergmann-Lips R, Luft F, Jordan J, Kettritz R: Niacin lowers serum phosphate and increases HDL cholesterol in dialysis patients. Clin J Am Soc Nephrol 2007;2:1249-1254.

-21 Bostom AG, Maclean AA, Maccubbin D, Tipping D, Giezek H, Hanlon WA: Extended-release niacin/laropiprant lowers serum phosphorus concentrations in patients with type 2 diabetes. J Clin Lipidol 2011;5:281-287.

22 Ix JH, Ganjoo P, Tipping D, Tershakovec AM, Bostom AG: Sustained hypophosphatemic effect of once-daily niacin/laropiprant in dyslipidemic CKD stage 3 patients. Am J Kidney Dis 2011;57:963-965.
23 Maccubbin D, Tipping D, Kuznetsova O, Hanlon WA, Bostom AG: Hypophosphatemic effect of niacin in patients without renal failure: a randomized trial. Clin J Am Soc Nephrol 2010;5:582-589.

$24 \mathrm{Hu}$ S, Shearer GC, Steffes MW, Harris WS, Bostom AG: Once-daily extended-release niacin lowers serum phosphorus concentrations in patients with metabolic syndrome dyslipidemia. Am J Kidney Dis 2011;57:181182.

25 Maccubbin D, Bays HE, Olsson AG, Elinoff V, Elis A, Mitchel Y, Sirah W, Betteridge A, Reyes R, Yu Q, et al: Lipid-modifying efficacy and tolerability of extended-release niacin/laropiprant in patients with primary hypercholesterolaemia or mixed dyslipidaemia. Int J Clin Pract 2008;62:1959-1970.

26 Paolini JF, Mitchel YB, Reyes R, Kher U, Lai E, Watson DJ, Norquist JM, Meehan AG, Bays HE, Davidson M, et al: Effects of laropiprant on nicotinic acid-induced flushing in patients with dyslipidemia. Am J Cardiol 2008; 101:625-630.

-27 Kaijser L, Eklund B, Olsson AG, Carlson LA: Dissociation of the effects of nicotinic acid on vasodilatation and lipolysis by a prostaglandin synthesis inhibitor, indomethacin, in man. Med Biol 1979;57:114-117.

$28 \mathrm{~K} / \mathrm{DOQI}$ clinical practice guidelines for bone metabolism and disease in chronic kidney disease. Am J Kidney Dis 2003;42(suppl 3):S1-S201

29 Levey AS, Stevens LA: Estimating GFR using the CKD Epidemiology Collaboration (CKDEPI) creatinine equation: more accurate GFR estimates, lower CKD prevalence estimates, and better risk predictions. Am J Kidney Dis 2010;55:622-627.

30 Levey AS, Stevens LA, Schmid CH, Zhang YL, Castro AF 3rd, Feldman HI, Kusek JW, Eggers $\mathrm{P}$, Van Lente F, Greene T, et al: A new equation to estimate glomerular filtration rate. Ann Intern Med 2009;150:604-612.

31 Ix JH, Katz R, Kestenbaum BR, de Boer IH, Chonchol M, Mukamal KJ, Rifkin D, Siscovick DS, Sarnak MJ, Shlipak MG: Fibroblast growth factor-23 and death, heart failure, and cardiovascular events in community-living individuals: CHS (Cardiovascular Health Study). J Am Coll Cardiol 2012;60:200-207.

- 32 Kidney Disease: Improving Global Outcomes (KDIGO) CKD-MBD Work Group: KDIGO clinical practice guideline for the diagnosis, evaluation, prevention, and treatment of chronic kidney disease-mineral and bone disorder (CKD-MBD). Kidney Int Suppl 2009; 113:S1-S130.
3 Kovesdy CP, Kuchmak O, Lu JL, KalantarZadeh K: Outcomes associated with phosphorus binders in men with non-dialysis-dependent CKD. Am J Kidney Dis 2010;56:842851.

34 Markel A: The resurgence of niacin: from nicotinic acid to niaspan/laropiprant. Isr Med Assoc J 2011;13:368-374.

35 Asano S, Suzuki A, Sekiguchi S, NishiwakiYasuda K, Shibata M, Itoh M: Effects of prostaglandin $\mathrm{D}_{2}$ on Na-dependent phosphate transport activity and its intracellular signaling mechanism in osteoblast-like cells. Prostaglandins Leukot Essent Fatty Acids 2009;81: 247-251.

- 36 Durand M, Gallant MA, de Brum-Fernandes AJ: Prostaglandin $\mathrm{D}_{2}$ receptors control osteoclastogenesis and the activity of human osteoclasts. J Bone Miner Res 2008;23:1097-1105.

- 37 Yue L, Durand M, Lebeau Jacob MC, Hogan P, McManus S, Roux S, de Brum-Fernandes AJ: Prostaglandin $\mathrm{D}_{2}$ induces apoptosis of human osteoclasts by activating the CRTH2 receptor and the intrinsic apoptosis pathway. Bone 2012;51:338-346.

38 Kawata T, Imanishi Y, Kobayashi K, Miki T, Arnold A, Inaba M, Nishizawa Y: Parathyroid hormone regulates fibroblast growth factor-23 in a mouse model of primary hyperparathyroidism. J Am Soc Nephrol 2007;18: 2683-2688.

-39 Chue CD, Townend JN, Moody WE, Zehnder D, Wall NA, Harper L, Edwards NC, Steeds RP, Ferro CJ: Cardiovascular effects of sevelamer in stage 3 CKD. J Am Soc Nephrol 2013;24:842-852.

40 Isakova T, Xie H, Yang W, Xie D, Anderson AH, Scialla J, Wahl P, Gutierrez OM, Steigerwalt S, He J, et al: Fibroblast growth factor-23 and risks of mortality and end-stage renal disease in patients with chronic kidney disease. JAMA 2011;305:2432-2439.

41 Dhingra R, Gona P, Benjamin EJ, Wang TJ, Aragam J, D'Agostino RB Sr, Kannel WB, Vasan RS: Relations of serum phosphorus levels to echocardiographic left ventricular mass and incidence of heart failure in the community. Eur J Heart Fail 2010;12:812-818.

-42 Foley RN, Collins AJ, Ishani A, Kalra PA: Calcium-phosphate levels and cardiovascular disease in community-dwelling adults: the Atherosclerosis Risk in Communities (ARIC) Study. Am Heart J 2008;156:556-563.

43 Kestenbaum B, Sampson JN, Rudser KD, Patterson DJ, Seliger SL, Young B, Sherrard DJ, Andress DL: Serum phosphate levels and mortality risk among people with chronic kidney disease. J Am Soc Nephrol 2005;16: 520-528.

-44 Tonelli M, Sacks F, Pfeffer M, Gao Z, Curhan G: Relation between serum phosphate level and cardiovascular event rate in people with coronary disease. Circulation 2005;112:26272633. 